\title{
Sentinel lymph node identification in colorectal cancer with in vivo mapping technique: rationale and development. Personal experience and literature review
}

\author{
Kiss Lorant ${ }^{1 *}$ and Kiss Roland ${ }^{2}$ \\ ${ }^{1}$ University Lucian Blaga Sibiu, Romania \\ ${ }^{2}$ Academic Emergency Hospital Sibiu, Romania
}

Received: March 02, 2015; Accepted: May 11, 2015; Published: May 20, 2015

*Corresponding author: Kiss Lorant, MD, PhD, Academic Emergency Hospital Sibiu, Romania, E-mail: drkisslorant@yahoo.com

\begin{abstract}
Background: Prognostic factors for colorectal carcinomas (CRC) must be detected to improve treatment. Metastatic spread to the draining lymph nodes (LN) is one of the most important prognostic factors for patients with CRC.

The purpose of this study was to determine with in vivo blue dye injection technique the sentinel lymph node (SLN) and the sentinel lymph node mapping (SLNM).
\end{abstract}

Methods: 140 patients who underwent curative resection for CRC were enrolled. We used for SLNs intraoperative identification the subserosal blue dye injection in vivo. All identified LNs were stained and examined by conventional hematoxylin and eosin method.

Results: After in vivo injection, all SLNs were examined by pathology. The median number of SLNs was 42 with in vivo injection. The detection rate of SLNs within location and that lymphatic drainage can be unpredictable at times underscore the importance of lymphatic mapping to precisely locate the sentinel node.

The SLN identification rate with the blue dye was $81 \%$, with 8 , $5 \%$ false negative rate, and 15, 3 upstaging rate.

Conclusion: The SLNs with in vivo blue dye subserosal injection is accurate in CRC. The SLN is sat uniformly peritumoral in location. The course of false negative SLNs $(8,5 \%)$ is a major issue to resolve before routinely using this technique in CRC management.

Keywords: sentinel lymph node; In vivo lymphography; Colon carcinoma

\section{Introduction}

In 1892 Herbert Snow noted that "the danger lies in the diffusion of malignant cells. These always implicate the nearest lymph glands... Palpable enlargement of these glands is, unfortunately, but a late symptom of deposits. We see the importance of securing the perfect eradication of these lymph glands."

In 1977 Cabanas reported a novel approach to staging carcinoma of the penis. Martin (1993) studied the blue stained node in melanoma, characterized as the "sentinel lymph node", as this lymph node was stained with injection of Isosulfan blue [1-3].

The most prognostic factor for predicting survival in CRC is the stage of the tumor during initial diagnosis, even though surgery alone is considered curative in most patients' cases. With the disease confined within the bowel wall (AJCC stage I/II), the survival decreases significantly by about $25-30 \%$, once the disease spreads beyond the bowel wall to draining lymph nodes (AJCC stage III).

Therefore, any diagnosis accuracy of nodal metastasis remains critical for proper prediction of survival and appropriate therapeutic planning. About $10-25 \%$ of patients considered to have localized disease (AJCC stage I/II) will develop progression of the disease within five years.

This systematic failure may be multifactorial, but many of these patients indeed had occult metastasis, which remained undetected by conventional pathologic examination [4-7].

Various methods have been developed to increase the incidence of detection of such nodal micrometastases, and most recently by reverse transcriptase polymerase chain reaction (RT-PCR) [8]. All of these methods have increased the rate of detection of lymph nodes metastases in colorectal cancer, but with an enormous burden to the pathologist in terms of time, cost and labor work. In this condition, sentinel lymph nodes (SLNs) mapping technique seems to be an ideal alternative for the accurate staging of patient's with colorectal cancer.

Since the 1990's this technique has been used for accurate staging of nodal metastasis in multiple solid tumors, including breast, [9-11] head and neck, thyroid, gastrointestinal, gynecological [12], lung [13] and colorectal cancer [14, 15].

The SLN is defined as the first to fourth node having direct drainage from the primary tumor site, and has the highest potential of harboring micrometastases when present [16].

If the SLNs can be identified during colorectal cancer surgery, these nodes can be specially tested by the pathologist for a 
detailed analysis by multilevel micro sections, IHC, and RT-PCR methods [17].

\section{Materials}

From January 2004 through December 2014, 140 consecutive patients with diagnosis of colorectal cancer, preoperatively N0 were prospectively studied with in vivo and ex vivo method for SLN detection. Preoperatively evaluation for all patients included a complete history and physical examination, routinely laboratory studies, including liver function study and carcinoembryonic antigen (CEA), colonoscopy and CT of the abdomen and pelvis.

In all patient's, an exploratory laparotomy was performed to find the extend of the primary tumor and any distinct metastases. For selective SLN mapping in colorectal cancer, the question is: how do we do it?

Some mobilization of the bowel along with the paracolic gutter was needed to deliver the bowel adjoining the tumor, near the surface. Metastatic dissection was kept at a minimum to prevent disruption of the lymphatic pathway.

\section{Method}

Once the tumor bearing area of the colon was isolated, 1-2 ml of patient Methylene blue dye $1 \%$ was injected subserosal by a tuberculin syringe, around the primary tumor in 4-th quadrants, in a circumferential manner (Figure 1).

Methylene blue dye 1\%, injected subserosal by a tuberculin syringe around the primary tumor in 4-th quadrants, in a circumferential manner (Figure 1).

Patient blue dye $1 \%$ is being injected subserosally around a tumor in the sigmoid colon of a 70 year female, and the mesentery was injected visually, to determine the SLNs, which were identified by uptake of the blue dye within the first 10 minutes of injection (Figure 2).

Care was taken not to inject into the lumen of the colon or rectum bowel. In low rectal cancer we use for subserosal transanal injection with a spinal needle. The blue dye travels quickly from the lymphatic channels to the draining lymphatic nodes. The SLNs are usually identified within the first five to seven minutes following the injection. The blue dye travels quickly from the lymphatic channels to the draining lymphatic nodes. After identification of the SLN we used two techniques: first was to marked with suture for future identification (Figure 3) or mapping (Figure 4). After identification of the SLNs, a bloc resection of carcinomas with lymphadenectomy was performed in the standard fashion, regardless of results of SLN mapping. Occasionally a blue node is identified outside of the usual lymphatic bearing area. This lymph node is considered as an SLN and included within the margins of the resection. This situation we have in one patient with transverse colon carcinoma, with identification of the "skip" dissemination in retrocecal areas of SLN (Figures 5-7).

Other unusual situation is represented by the presence of
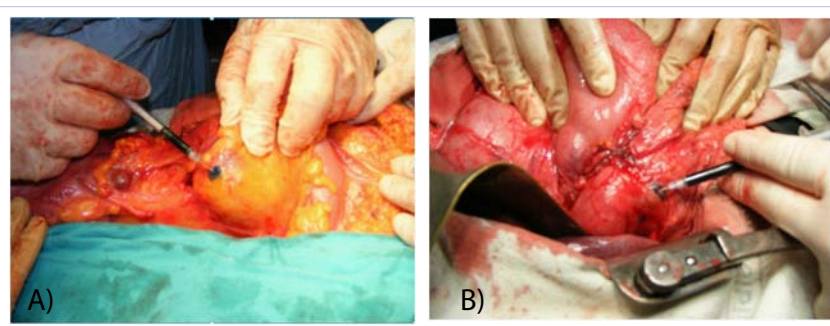

Figure 1: Methylene blue dye 1\%, injected subserosal by a tuberculin syringe around the primary tumor in 4-th quadrants, in a circumferential manner.

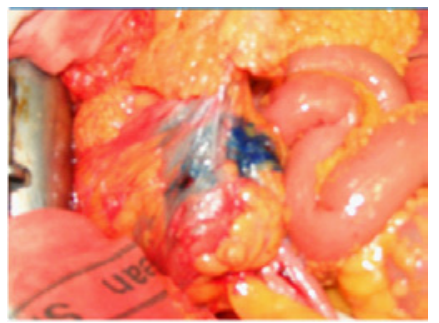

Figure 2: Patient blue dye $1 \%$ is being injected subserosally and the mesentery was injected visually.

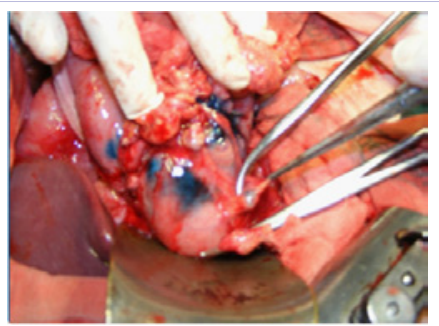

Figure 3: Lymphatic mapping of the colon cancer demonstrating a blue stained lymphatic channel and sentinel node.

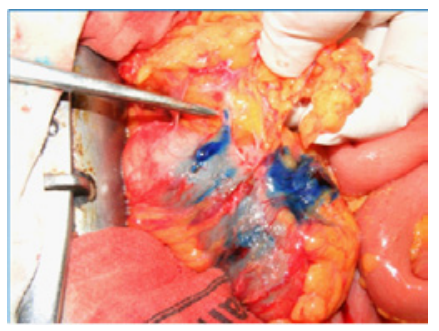

Figure 4: After identification of the SLN we used two techniques: first was to marked with suture for future identification.

fatty mesentery, required by the limited surgical dissection of the mesentery fat, to identify the stained LNs. For this clinical study we have to get approval from ethical commission and from the patients.

\section{Pathological Examination}

The surgical specimens were sent to the pathology in a fresh state, and each stained LN was considered as an SLN, thus being 


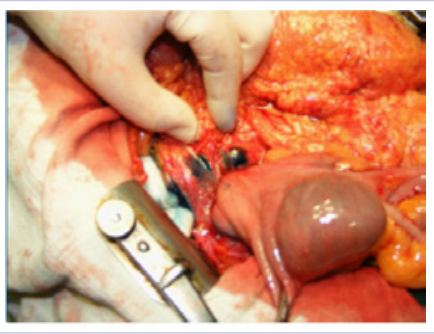

Figure 5: The marked SLN.
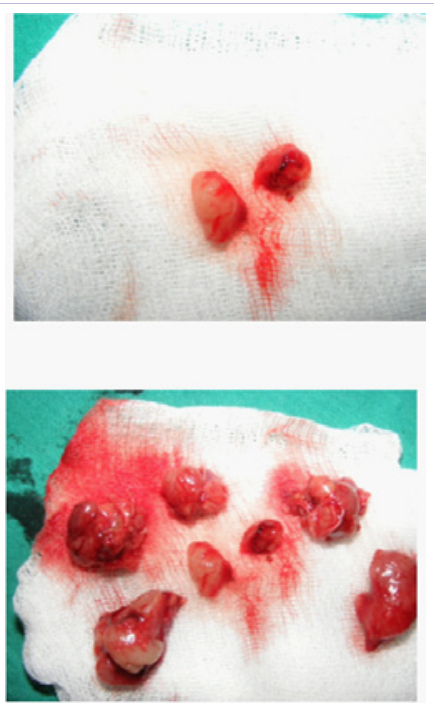

Figure 6: The resected-mapping SLN.

removed from the specimen, and sectioned grossly at about 2 - $3 \mathrm{~mm}$. If the SLN were negative after standard H-E staining (hematoxilin-eosin) they were sectioned and examined in four levels by H-E, or selective cases by IHC (immunohistochemistry). The presence of 0.2 and $2.0 \mathrm{~mm}$ metastases were considered as micrometastases, and then smaller than $0.2 \mathrm{~mm}$ were considered as isolated tumor cells.

The presence of micro metastases or isolated tumor cells after IHC in negative LNs status after H-E staining was defined as upstaging $[15,16]$. We defined the accuracy of SLN identification as the proportion of positive mapping of SLN. False-negative were the proportion of cases with identification of SLNs and having SLN without invasion, but tumor-positive SLNs.

We defined upstaging as the proportion of cases with negative lymph nodes found by $\mathrm{H}-\mathrm{E}$, but with micrometastases by focused examination of the SLN. For statistical analysis we used a Fisher exact test or $\mathrm{X}^{2}$ test, and the Student's test for interval scaled variables. All test were performed using SPSS software (version 150.0 SPSS) INC Chicago (IC USA). A p value $\leq 0.05$ was considered for significant difference.

\section{Results}

In the present study 140 patients with colorectal cancer took part. The demographic features, tumor location, tumor stage, site of the tumor and histology are shown in Table 1. The result obtained with in vivo SLNs mapping are shown in Table 2.

The SLN identification rates were $81 \%$ with the in vivo injection, with accuracy in $87 \%$ of cases. Of the 72 tumors with positive SLNs, in 26 cases $(36,1 \%)$ the SLNs were the only sites of metastasis and 4 patients $(15,3 \%)$ were upstaged.

False negative SLN mapping were detected in 12 cases, these cases were located in the right colon, and upper rectum, and all negative cases had a tumor size greater than p T3 (Table 3).

All but 2 of the 12 false negative cases had a tumor greater then $5,0 \mathrm{~cm}$, and greater than pT3. We observed in 14 patients a failure in the detection of the SLN, 4 of which were directly associated with technical trouble.

None of the patients presented an adverse reaction associated with intraoperative methylene blue dye injection.

\section{Discussion}

In our analysis, the global sensibility of SLNM was 77\%, with $87 \%$ accuracy. SLNM is not currently approved for the treatment of colon cancer, but is tested in clinical trials.

For colorectal cancer we needed to evaluate the extrusion
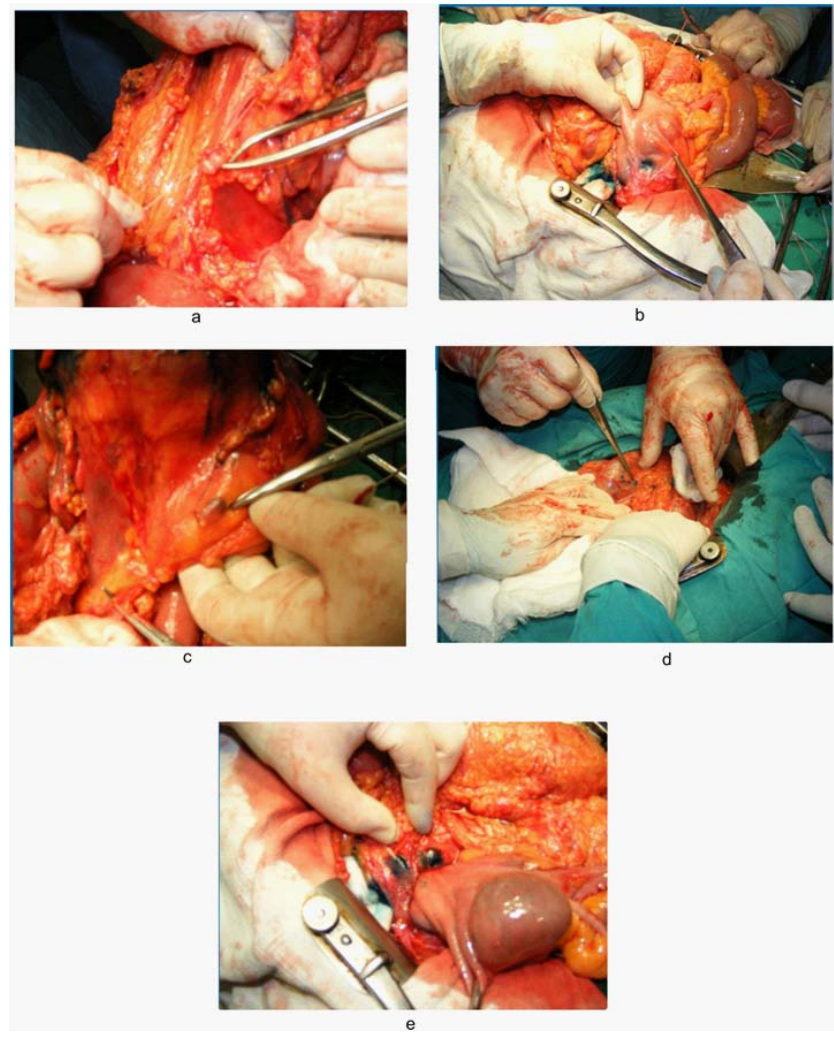

Figure 7: Retrocecal "skip" metastasis with SLN in transvers colon carcinoma.

a: colon transverse carcinoma, b,e: skip metastasis around the caecum, c: SLN and the mesocolon, d: SLN identification int the right mesocolon 
Table 1: Characteristic of patients: $\mathrm{N}=140$.

\begin{tabular}{|l|c|c|}
\hline Characteristics & Patients with in vivo & P value \\
\hline Age & $62(10.1)$ & 0.256 \\
\hline Serum CEA (mg/ml) & $5.9(14.0)$ & 0.78 \\
\hline Tumor size & $4.2(1.6)$ & 0.64 \\
\hline Primary tumor site: & 47 & 0.52 \\
Right colon & 13 & \\
Transverse colon & 10 & 0.190 \\
Left colon & 46 & \\
Sigmoid colon & 24 & \\
Rectum & 10 & 0.952 \\
\hline T stage: & 30 & \\
T1 & 100 & \\
T2 & 140 & \\
T3 & & \\
\hline Nr. of patients & 62 & 0.35 \\
\hline AJCC stage: & 78 & \\
I/II & & \\
III & 40 & \\
\hline Pathology: & 95 & \\
Well differentiated & 5 & \\
Moderate differentiated & & \\
Undifferentiated & & \\
\hline
\end{tabular}

Table 2: Results of SLN identification and mapping with in vivo injection technique.

\begin{tabular}{|c|c|c|c|c|c|c|}
\hline Technique & Detection rate & Nr. of SLNs & Accuracy & Sensibility & False (-) note & Upstaging \\
\hline In vivo & $114 / 140(81 \%)$ & $2,3+0,8$ & $120 / 140(87 \%)$ & $107 / 140(77 \%)$ & $\begin{array}{c}12 / 140 \\
(8.5 \%)\end{array}$ & $\begin{array}{c}4 / 26 \\
(15.4 \%)\end{array}$ \\
\hline
\end{tabular}

Table 3: 12 Cases with false-negative SLN mapping.

\begin{tabular}{|c|c|c|c|c|c|c|}
\hline Cases & Nr. of SLN & TNM stage & $\begin{array}{c}\text { Lymphatic } \\
\text { vascular invasion }\end{array}$ & Location & Tumor size (cm) & $\begin{array}{c}\text { Histology } \\
\text { (differentiated) }\end{array}$ \\
\hline 1 & 2 & T3N2M0 & $+/+$ & Cecum & 5.5 & Moderate \\
\hline 2 & 1 & T3N1M0 & $+/+$ & Cecum & 5.2 & Moderate \\
\hline 3 & 1 & T3N1M0 & $-/-$ & Ascendant Colon & 6.0 & Undifferentiated \\
\hline 4 & 2 & T3N2M0 & $-/+$ & Flexura Coli Hepatis & 5.6 & 5 \\
\hline 5 & 3 & T3N1M0 & $+/-$ & Sigmoid & 5.6 & Mndifferentiated \\
\hline 6 & 2 & T3N1M0 & $+/-$ & Descendent Colon & 3.6 & Moderate \\
\hline 7 & 3 & T2N1M0 & $+/+$ & Upper Rectum & Moderate \\
\hline 8 & 2 & T3N1M0 & $+/+$ & Upper Rectum & 6.5 & Moderate \\
\hline 9 & 2 & T3N2M0 & $+/+$ & Colon Transverse & 5.6 & Moderate \\
\hline 10 & 2 & T3N1M0 & $+/+$ & Ascendant Colon & 5.4 & Undifferentiated \\
\hline 11 & 2 & T3N1M0 & $+/+$ & Descendent Colon & 5.2 & Moderate \\
\hline 12 & 3 & T3N1M0 & $+/-$ & Sigmoid & 5.2 & Moderate \\
\hline
\end{tabular}

of the disease more precisely. It's not acceptable to miss value extrusion because there is no other prognostic factor that should be used to justify the adjuvant treatment our analysis showed an $8.5 \%$ median risk of false-negative results. If we consider all studies published on breast cancer (65\%), where SLN has been extensively studied, we have the same 8.4\% (0-29\%) false negative rate [18].

In breast cancer SLNM is proposed for T1-T2 tumors [19]. In the series of CRC(s) we often found more than half of the patients with T3-T4 tumors [20-24].

In CRC(s) we are shown that a massive lymph node 
involvement was the cause of the high false - negative rate of SLNM, similar observations were published from others too [25]

Thus, for future studies of CRC it will be necessary to stratify patients according to their T stage.

Elsewhere, a large study [26] found a higher success rate of SLNM for colon cancer versus rectal cancer, but nodal upstaging, skip metastases and occult metastases were similar to the two sites.

For trials that included more than 100 patients, the false negative rate was $6.7 \%$ versus $9.0 \%$ for trials including fewer than 100 patients. In the present study with 140 colon and rectal carcinoma the false - negative rate was $8.3 \%$.

This technique seems operator dependent, and a learning curve is probably necessary to obtain good results for SLNM. A study by Paramo et al detailed the number of cases (eight) required to be sure to obtain reproducible results for CRC [20,21]

No standardization exist concerning the most optimal technique for SLNM, previous studies with visible dye and lymphoscintigraphy with in vivo or ex vivo setting, reported different times of mapping, variable injection sites (subserosal, submucosal, or peritumoral) and variable a both definitions of upstaging [27-34].

In a recent multicenter trial [32] the SLNM rate in colon cancer was $92 \%$, with a false-negative rate of $54 \%$. In this trial 72 patients were enrolled by 25 surgeons at 13 institutions, with 18 surgeons $(72 \%)$ performing fewer than five SLNM procedures.

In another multicenter study the surgeons performed of blue dye with a $47-54 \%$ false - negative rate $[26,33]$, in contrast with the results of experienced surgeons in more than 20-30 cases $[15,33,35]$.

Data on SLNM in rectal cancer are limited and several studies have shown that SLN detection in rectal cancer is unreliable [31], the applicability of SLN procedure is highly limited due to the narrow space around the bulky mesentery, infraperitoneal location, and complex lymphatic drainage. In infraperitoneal rectum carcinoma we use the endoanal subserosal injection in the tumor site. Because we have a limited experience with transanal injection of the blue dye, in the current study we adopted narrow indication of rectal cancer patients, and only the cases of the upper rectum which located above the peritoneal reflection were eligible to this study.

Isosulfan blue is the popular choice for lymphatic mapping in CRC, the methylene blue dye is efficacious too and cost effective as an alternative to isosulfan blue dye [36-43].

With CRC, according to the UICC recommendations, a minimum of 15 lymph nodes is adequate for accurate PM staging [44]. Joseph et al noted that the more lymph nodes that were sampled, the greater was the number of patients upstaging. For T1-2 lesions, more than $18 \mathrm{LN}(\mathrm{s})$ must be found [45]. Certainly the number of lymph nodes that should be examined is crucial to a proper diagnosis. The meta analysis published from Gaetan et al. [46] have considered that conventional examination of selected lymph nodes in a CRC specimen is less informative than for used examination of SLNs identified during SLNM.

In fact the median rate of patients (9\%) who were upstaged could justify a focused SLN examination. In present study we have $15.3 \%$ upstaging with in vivo SLNM.

Presentation of the false - negative SLN data varies in the literature [46-50]. The varying definition of SLN positivity is a major reason for the large discrepancy in reported false negative rates [51,52].

The extension of the disease contributes to false - negative SLN staging as well. Tumor replaced lymph nodes, those with extra nodal disease extrusion, and nodes directly invaded by tumor are unlikely to stain blue after peritumoral subserosal injection of blue dye, because of lymphatic channel obstruction by tumor $[49,53,54]$.

In tumors located in the rectum, particularly inaccessible cancers located extra peritoneally or those treated with preoperative radiation, are associated with high false - negative results $[50,53]$. In the in vivo SLNM for rectal cancer, to identify the blue node, must disrupting the mesenterium specimen postoperatively. As such rectal cancers have represented only $13 \%$ of studies evaluating lymphatic mapping for CRC [55].

A recent prospective multicenter trial demonstrated that detection rates with sensitivity were significantly influenced by patient, and disease specific factors [56]. In the present study we have 12 cases with false - negative results, and the majority of these were advanced carcinomas with T3 tumor and large $(>5$ $\mathrm{cm}$ ), suggesting that the large, and more than T2 tumors may alter the lymphatic channels and obstruct a duct by tumor cells or deposits.

For this reason an guideline for the SLNM procedure would be important to reduce false - negative rates [57-67].

For this study we have a patient accept and the accept from the ethics commission of the Emergency Academic Hospital.

\section{Conclusion}

The present study indicated that SLNM with in vivo method is accurate in CRC. Based on the results of the present study on the use of SLNM in CRC patients should use blue dye for reasons of simplity, be performed by experienced surgeons and pathologists.

The SLN is sat in uniformly peritumoral in location and that lymphatic drainage can be unpredictable at times, underscore the importance of lymphatic mapping to precisely locate the SLN.

\section{References}

1. Association of Comprehensive Cancer Centres. Guideline 'Colon cancer'. 2008

2. Thompson JF. The Sydney Melanoma Unit experience of sentinel lymphadenectomy for melanoma. Ann Surg Oncol. 2001;8:11599898. 
3. Bembenek A, String A, Gretschel S, Schlag PM. Technique and clinical consequences of sentinel lymph node biopsy in colorectal cancer. Surg Oncol. 2008;17:18571920. doi:10.1016/j.suronc.2008.05.003.

4. Pickren JW. Significance of occult metastases. A study of breast cancer Cancer. 1961;14:14486400.

5. Turner RR, Ollila DW, Stern S, Giuliano AE. Optimal histopathologic examination of the sentinel lymph node for breast carcinoma staging Am J Surg Pathol. 1999;23:10078915.

6. Haboubi NY, Abdalla SA, Amini S, Clark P, Dougal M, Dube A, et al The novel combination of fat clearance and immunohistochemistry improves prediction of the outcome of patients with colorectal carcinomas: a preliminary study. Int J Colorect Dis. 1998;13. doi:10.1007/s003840050143.

7. Greenson JK, Isenhart CE, Rice R, Mojzisik C, Houchens D, Martin EW. Identification of occult micrometastases in pericolic lymph nodes of Duke's B colorectal cancer patients using monoclonal antibodies against cytokeratin and CC49. Correlation with long-term survival. Cancer. 1994;73:7507795

8. Mori $\mathrm{M}$, Mimori $\mathrm{K}$, Inoue $\mathrm{H}$, Barnard GF, Tsuji $\mathrm{K}$, Nanbara $\mathrm{S}$ et al. Detection of cancer micrometastases in lymph nodes by reverse transcriptase-polymerase chain reaction. Cancer Res. 1995;55:7542169.

9. Waters GS, Geisinger KR, Garske DD, Loggie BW, Levine EA. Sentine lymph node mapping for carcinoma of the colon: a pilot study. Am Surg. 2000;66:11261621.

10. Osako T, Iwase T, Kimura K, Yamashita K, Horii R, Yanagisawa A, et al. Intraoperative molecular assay for sentinel lymph node metastases in early stage breast cancer: a comparative analysis between one-step nucleic acid amplification whole node assay and routine frozen section histology. Cancer. 2011;117:21437889. doi:10.1002/cncr.26060.

11. Giuliano AE, Kirgan DM, Guenther JM, Morton DL. Lymphatic mapping and sentinel lymphadenectomy for breast cancer. Ann Surg 1994;220:8092905.

12. Bilchik AJ, Giuliano A, Essner R, Bostick P, Kelemen P, Foshag LJ, et al. Universal application of intraoperative lymphatic mapping and sentinel lymphadenectomy in solid neoplasms. Cancer J Sci Am. 1998;4:9853133

13. Little AG, DeHoyos A, Kirgan DM, Arcomano TR, Murray KD. Intraoperative lymphatic mapping for non-small cell lung cancer: The sentinel node technique. The Journal of Thoracic and Cardiovascular Surgery. 1999;117. doi:10.1016/S0022-5223(99)70415-0.

14.Yi M, Giordano SH, Meric-Bernstam F, Mittendorf EA, Kuerer HM, Hwang RF, et al. Trends in and outcomes from sentinel lymph node biopsy (SLNB) alone vs. SLNB with axillary lymph node dissection for node-positive breast cancer patients: experience from the SEER database. Ann Surg Oncol. 2010;17 Suppl 3:20853057. doi:10.1245/ s10434-010-1253-3

15. Yi M, Giordano SH, Meric-Bernstam F, Mittendorf EA, Kuerer HM, Hwang RF, et al. Trends in and outcomes from sentinel lymph node biopsy (SLNB) alone vs. SLNB with axillary lymph node dissection for node-positive breast cancer patients: experience from the SEER database. Ann Surg Oncol. 2010;17 Suppl 3:20853057. doi:10.1245/ s10434-010-1253-3.

16. Bilchik A, Nissan A, Wainberg Z, Shen P, McCarter M, Protic M et al. Surgical quality and nodal ultrastaging is associated with long-term disease-free survival in early colorectal cancer: an analysis of 2 international multicenter prospective trials. Ann Surg 2010;252:20739847. doi:10.1097/SLA.0b013e3181f19767.

17. Saha S, Wiese D, Badin J, Beutler T, Nora D, Ganatra BK, et al. Technical details of sentinel lymph node mapping in colorectal cancer and its impact on staging. Ann Surg Oncol. 2000;7:10761790.

18. Saha S, Sehgal R, Seghal R, Patel M, Doan K, Dan A, et al. A multicenter trial of sentinel lymph node mapping in colorectal cancer: prognostic implications for nodal staging and recurrence. Am J Surg. 2006;191:16490536. doi:10.1016/j.amjsurg.2005.10.028.

19. Bilchik AJ, Saha S, Wiese D, Stonecypher JA, Wood TF, Sostrin S, et al. Molecular staging of early colon cancer on the basis of sentinel node analysis: a multicenter phase II trial. J Clin Oncol. 2001;19:11181678.

20. Lyman GH, Giuliano AE, Somerfield MR, Benson AB, Bodurka DC, Burstein HJ, et al. American Society of Clinical Oncology guideline recommendations for sentinel lymph node biopsy in early-stage breast cancer. J Clin Oncol. 2005;23:16157938. doi:10.1200/ JC0.2005.08.001.

21. Saha S, Sehgal R, Seghal R, Patel M, Doan K, Dan A, et al. A multicenter trial of sentinel lymph node mapping in colorectal cancer: prognostic implications for nodal staging and recurrence. Am J Surg. 2006;191:16490536. doi:10.1016/j.amjsurg.2005.10.028.

22. Codignola C, Zorzi F, Zaniboni A, Mutti S, Rizzi A, Padolecchia E, et al. Is there any Role for Sentinel Node Mapping in Colorectal Cancer Staging? Personal Experience and Review of the Literature. Jpn J Clin Oncol. 2005;35:16275673. doi:10.1093/jjco/hyi182.

23. Braat AE, Oosterhuis JWA, Moll FCP, de Vries JE, Wiggers T. Sentinel node detection after preoperative short-course radiotherapy in rectal carcinoma is not reliable. Br J Surg. 2005;92:16231281. doi:10.1002/ bjs. 5169 .

24. Broderick-Villa G, Amr D, Haigh PI, O’Connell TX, Danial T, Difronzo LA. Ex vivo lymphatic mapping: a technique to improve pathologic staging in colorectal cancer. Am Surg. 2004;70:15586501.

25. Paramo JC, Summerall J, Poppiti R, Mesko TW. Validation of sentinel node mapping in patients with colon cancer. Ann Surg Oncol. 2002;9:12095970.

26. Faerden AE, Sjo OH, Sjo O, Andersen SN, Hauglann B, Nazir N, et al. Sentinel node mapping does not improve staging of lymph node metastasis in colonic cancer. Dis Colon Rectum. 2008;51:18259817. doi:10.1007/s10350-007-9185-0.

27. Lasser P, Cote JF, Sabourin JC, et al. (2003) (is sentinel lymph node mapping relevant for colon cancer: a feasibility study.) Ann Chir 128:433-437

28. Redston M, Compton CC, Miedema BW, Niedzwiecki D, Dowell JM, Jewell SD, et al. Analysis of micrometastatic disease in sentinel lymph nodes from resectable colon cancer: results of Cancer and Leukemia Group B Trial 80001. J Clin Oncol. 2006;24:16418493. doi:10.1200/ JC0.2005.03.6038.

29. Wong JH, Johnson DS, Namiki T, Tauchi-Nishi P. Validation of ex vivo lymphatic mapping in hematoxylin-eosin node-negative carcinoma of the colon and rectum. Ann Surg Oncol. 2004;11:15249341. doi:10.1245/ASO.2004.11.026.

30. Bell SW, Mourra N, Fléjou JF, Parc R, Tiret E. Exvivo sentinel lymph node mapping in colorectal cancer. Dis Colon Rectum. 2005;48:15690661.

31.Dan AG, Saha S, Monson KM, Wiese D, Schochet E, Barber KR, et al. $1 \%$ lymphazurin vs $10 \%$ fluorescein for sentinel node mapping in 
colorectal tumors. Arch Surg. 2004;139:15545563. doi:10.1001/ archsurg.139.11.1180.

32. Demirbas S, Ince M, Baloglu H, Celenk T. Should sentinel lymph node mapping be performed for colorectal cancer? Turk J Gastroenterol. 2004;15:15264120.

33. Bertagnolli M, Miedema B, Redston M, Dowell J, Niedzwiecki D, Fleshman J, et al. Sentinel node staging of resectable colon cancer: results of a multicenter study. Ann Surg. 2004;240:15383790.

34. Baton O, Lasser P, Sabourin J-C, Boige V, Duvillard P, Elias D, et al. Ex vivo sentinel lymph node study for rectal adenocarcinoma: preliminary study. World J Surg. 2005;29:16086211. doi:10.1007/ s00268-005-7867-0.

35. Bilchik AJ, DiNome M, Saha S, Turner RR, Wiese D, McCarter M, et al. Prospective multicenter trial of staging adequacy in colon cancer: preliminary results. Arch Surg. 2006;141:16785352. doi:10.1001/ archsurg.141.6.527.

36. Wong JH, Johnson DS, Namiki T, Tauchi-Nishi P. Validation of ex vivo lymphatic mapping in hematoxylin-eosin node-negative carcinoma of the colon and rectum. Ann Surg Oncol. 2004;11:15249341. doi:10.1245/ASO.2004.11.026

37. Bembenek A, Rau B, Moesta T, Markwardt J, Ulmer C, Gretschel S, et al. Sentinel lymph node biopsy in rectal cancer--not yet ready for routine clinical use. Surgery. 2004;135:15118586. doi:10.1016/j. surg.2003.10.004.

38. Broderick-Villa G, Ko A, O'Connell TX, Guenther JM, Danial T, DiFronzo LA. Does tumor burden limit the accuracy of lymphatic mapping and sentinel lymph node biopsy in colorectal cancer? Cancer J. 2002;8:12500853.

39. Tsioulias GJ, Wood TF, Spirt M, Morton DL, Bilchik AJ. A novel lymphatic mapping technique to improve localization and staging of early colon cancer during laparoscopic colectomy. Am Surg. 2002;68:12132733.

40. Stojadinovic A, Allen PJ, Protic M, Potter JF, Shriver CD, Nelson JM, et al. Colon sentinel lymph node mapping: practical surgical applications. J Am Coll Surg. 2005;201:16038828. doi:10.1016/j. jamcollsurg.2005.01.020.

41. Wong JH, Johnson DS, Namiki T, Tauchi-Nishi P. Validation of ex vivo lymphatic mapping in hematoxylin-eosin node-negative carcinoma of the colon and rectum. Ann Surg Oncol. 2004;11:15249341. doi:10.1245/ASO.2004.11.026.

42. Bell SW, Mourra N, Fléjou JF, Parc R, Tiret E. Ex vivo sentinel lymph node mapping in colorectal cancer. Dis Colon Rectum. 2005;48:15690661.

43. Demirbas S, Ince M, Baloglu H, Celenk T. Should sentinel lymph node mapping be performed for colorectal cancer? Turk J Gastroenterol. 2004;15:15264120.

44. Chang GJ, Kaiser AM, Mills S, Rafferty JF, Buie WD, Standards Practice Task Force of the American Society of Colon and Rectal Surgeons. Practice parameters for the management of colon cancer. Dis Colon Rectum. 2012;55:22810468. doi:10.1097/DCR.0b013e3182567e13.

45. Joseph NE, Sigurdson ER, Hanlon AL, Wang H, Mayer RJ, MacDonald JS, et al. Accuracy of determining nodal negativity in colorectal cancer on the basis of the number of nodes retrieved on resection. Ann Surg Oncol. 2003;10:12679304.

46. Wiese DA, Saha S, Badin J, Ng PS, Gauthier J, Ahsan A, et al. Pathologic evaluation of sentinel lymph nodes in colorectal carcinoma Arch Pathol Lab Med. 2000;124:11100053. doi:10.1043/0003-
9985(2000)124<1759:PEOSLN>2.0.C0;2.

47.Turner RR, Nora DT, Trocha SD, Bilchik AJ. Colorectal carcinoma nodal staging. Frequency and nature of cytokeratin-positive cells in sentinel and nonsentinel lymph nodes. Arch Pathol Lab Med. 2003;127:12741889. doi:10.1043/1543-2165(2003)127<673:CCNS $>2.0 . \mathrm{CO} ; 2$

48. Viehl CT, Hamel CT, Marti WR, Guller U, Eisner L, Stammberger U, et al. Identification of sentinel lymph nodes in colon cancer depends on the amount of dye injected relative to tumor size. World J Surg. 2003;27:14595521. doi:10.1007/s00268-003-7086-5.

49.ls SLNM in colorectal cancer a future prognostic factor? A metaanalysis Suetan Des Suet, Bunord Uzzan, Patricle Nicolas et al. Worldl Surg 2007,31,1304-1312

50. Joosten JJ, Strobbe LJ, Wauters CA, Pruszczynski M, Wobbes T, Ruers T]. Intraoperative lymphatic mapping and the sentinel node concept in colorectal carcinoma. Br J Surg. 1999;86:10215818. doi:10.1046/ j.1365-2168.1999.01051.x.

51. Tsioulias GJ, Wood TF, Morton DL, Bilchik AJ. Lymphatic mapping and focused analysis of sentinel lymph nodes upstage gastrointestinal neoplasms. Arch Surg. 2000;135:10922254.

52. Bertagnolli M, Miedema B, Redston M, Dowell J, Niedzwiecki D, Fleshman J, et al. Sentinel node staging of resectable colon cancer: results of a multicenter study. Ann Surg. 2004;240:15383790.

53. Feig BW, Curley S, Lucci A, Hunt KK, Vauthey JN, Mansfield PF, et al. A caution regarding lymphatic mapping in patients with colon cancer. Am J Surg. 2001;182:11839343.

54. Wood TF, Saha S, Morton DL, Tsioulias GJ, Rangel D, Hutchinson W, et al. Validation of lymphatic mapping in colorectal cancer: in vivo, ex vivo, and laparoscopic techniques. Ann Surg Oncol. 2001;8:11258780.

55. Paramo JC, Summerall J, Poppiti R, Mesko TW. Validation of sentinel node mapping in patients with colon cancer. Ann Surg Oncol. 2002;9:12095970.

56. Mulsow J, Winter DC, O'Keane JC, O'Connell PR. Sentinel lymph node mapping in colorectal cancer. Br J Surg. 2003;90:12808612. doi:10.1002/bjs.4217.

57. Smith FM, Coffey JC, Khasri NM, Walsh MF, Parfrey N, Gaffney E et al. Sentinel nodes are identifiable in formalin-fixed specimens after surgeon-performed ex vivo sentinel lymph node mapping in colorectal cancer. Ann Surg Oncol. 2005;12:15886906. doi:10.1245/ AS0.2005.08.019.

58. Feig BW, Curley S, Lucci A, Hunt KK, Vauthey JN, Mansfield PF, et al. A caution regarding lymphatic mapping in patients with colon cancer. Am J Surg. 2001;182:11839343.

59. Bendavid Y, Latulippe JF, Younan RJ, Leclerc YE, Dube S, Heyen F, et al. Phase I study on sentinel lymph node mapping in colon cancer: A preliminary report*. J Surg Oncol. 2002;79. doi:10.1002/jso.10052.

60. Saha S, Dan AG, Berman B, Wiese D, Schochet E, Barber K, et al. Lymphazurin $1 \%$ versus $99 \mathrm{mTc}$ sulfur colloid for lymphatic mapping in colorectal tumors: a comparative analysis. Ann Surg Oncol. 2004;11:14699029.

61. Mulsow J, Winter DC, O'Keane JC, O'Connell PR. Sentinel lymph node mapping in colorectal cancer. Br J Surg. 2003;90:12808612. doi:10.1002/bjs.4217.

62.Wiley: TNM Classification of Malignant Tumours, 7th Edition - Leslie 
H. Sobin, Mary K. Gospodarowicz, Christian Wittekind n.d. http:// as.wiley.com/WileyCDA/WileyTitle/productCd-1444332414.html (accessed June 29, 2015).

63. Cox ED, Kellicut D, Adair C, Marley K, Otchy DP, Peoples GE. Sentinel lymph node evaluation is technically feasible and may improve staging in colorectal cancer. Curr Surg. 2002;59:16093152.

64. Wiese D, Sirop S, Yestrepsky B, Ghanem M, Bassily N, Ng P, et al. Ultrastaging of sentinel lymph nodes (SLNs) vs. non-SLNs in colorectal cancer--do we need both? Am J Surg. 2010;199:20226909. doi:10.1016/j.amjsurg.2009.08.032.

65. Faerden AE, Sjo OH, Bukholm IRK, Andersen SN, Svindland A,
Nesbakken A, et al. Lymph node micrometastases and isolated tumor cells influence survival in stage I and II colon cancer. Dis Colon Rectum. 2011;54:21228669. doi:10.1007/DCR.0b013e3181fd4c7c.

66. Salhab M, Patani N, Mokbel K. Sentinel lymph node micrometastasis in human breast cancer: an update. Surg Oncol. 2011;20:21788132. doi:10.1016/j.suronc.2011.06.006.

67. Baton O, Lasser P, Sabourin J-C, Boige V, Duvillard P, Elias D, et al. Ex vivo sentinel lymph node study for rectal adenocarcinoma: preliminary study. World J Surg. 2005;29:16086211. doi:10.1007/ s00268-005-7867-0. 